\title{
NHậN THỨC VỀ VIỆC SỬ DỤNG SẢN PHẨM NĂNG LƯợNG MẶT TRỜI Ở VIỆT NAM
}

\author{
Đinh Thị Trang, Nguyễn Lâm Mỹ Anh, Bùi Hiểu Ly
}

Hà Nội, ngày 23 tháng 12 năm 2021

Preprint DOI: $\underline{10.31219 / 0 s f . i o / s c 84 j}$

Việt Nam đang trở thành một hình mẫu của các nước đang phát triển về xóa đói giảm nghèo và phát triển bền vững. Sau hơn 30 năm đổi mới, nền kinh tế của Việt Nam đã phát triển vượt bậc (Chính \& Hoàng, 2009), quy mô nền kinh tế từ 6,3 tỷ đô la năm 1989 đến 268 tỷ đô la vào năm 2020 (Mai Trung Dũng, 2021).

Duy trì tăng trưởng kinh tế luôn ở mức cao, trong khi quy mô nền kinh tế ngày càng lớn, Việt Nam đang đối diện với tình trạng thiếu hụt năng lượng. Việt Nam đang phải đối mặt với nguy cơ thiếu điện cao trong giai đoạn 2021-2025, nhất là năm 2023 dự đoán thiếu hụt khoảng 12 tỷ kWh (Hoàng Công Tuấn, 2020).

Vào năm 2017, Thủ tướng đã ký Quyết định số 11/2017/QĐ-TTg để hỗ trợ phát triển các dự án điện mặt trời, tuy nhiên đến năm 2019 chính sách FIT mới mang đến sự bùng nổ về điện mặt trời, đưa Việt Nam trở thành nước dẫn đầu về điện mặt trời của ASEAN. Và mới đây, trong làn sóng của Covid-19, Thủ tướng Chính phủ đã ban hành Quyết định số 13/2020/QĐ-TTg về cơ chế khuyến khích phát triển điện mặt trời vào ngày 6/4/2020, thiết lập khung chính sách cho thị trường điện mặt trời trên mái nhà rộng lớn của Việt Nam (Jinko, 2020).

Tiêu dùng xanh hiện được xem là xu hướng tiêu dùng của thế kỷ khi môi trường đang được xem là mối quan tâm lớn của nhiều quốc gia trên thế giới, trong đó có Việt Nam. Một trong những nguồn năng lượng xanh mà Việt Nam có thế mạnh nổi bật do 
nằm trong khu vực có cường độ bức xạ mặt trời tương đối cao, đó chính là nguồn năng lượng mặt trời.

Theo số liệu do Ngân hàng Thế giới công bố cho thấy Việt Nam có trung bình 1.600-2.700 giờ có ánh nắng mặt trời và bức xạ trực tiếp thông thường trung bình là 4-5 kWh trên mỗi mét vuông một ngày (Phạm Sơn, 2017). Tiềm năng phát triển mạnh mẽ nguồn năng lượng tái tạo này ở Việt Nam mang đến cho người tiêu dùng nhiều sự lựa chọn, tuy nhiên tiềm năng của sản phẩm là chưa đủ, yếu tố đặc biệt ảnh hưởng đến tiêu dùng sản phẩm năng lượng mặt trời là nhận thức người dân với năng lượng mặt trời.

Nhận thức của người tiêu dùng Việt Nam về các sản phẩm năng lượng mặt trời ngày càng có vai trò to lớn trong việc thúc đẩy tiêu dùng nguồn năng lượng sạch này tại Việt Nam. Nhận thức của người dân về môi trường và các vấn đề liên quan đến môi trường có liên hệ mật thiết đến hành vi tiêu dùng của họ, hướng hộ đến tiêu dùng sản phẩm sạch - năng lượng mặt trời. Theo nghiên cứu trước, Murphy và cộng sự (1978) đã chỉ ra rằng mối quan tâm của người tiêu dùng đến với môi trường dựa vào các đặc tính và lợi ích của nó với môi trường (Lan Anh, 2021). Cái nhìn đúng đắn và khách quan về sản phẩm cũng mang người tiêu dùng đến gần với mặt hàng tiêu dùng hơn. Sản phẩm năng lượng mặt trời mang những lợi ích đặc biệt đến với người tiêu dùng Việt: giảm tác động đến môi trường, nguồn năng lượng vô hạn, tiết kiệm hóa đơn điện, sản phẩm mang tính hiện đại và thẩm mỹ, tính năng ưu việt và có độ bền cao... Bên cạnh đó, quyết định mua hàng của người tiêu dùng con bị ảnh hưởng bởi yếu tố giá cả. Người tiêu dùng Việt luôn thích mua hoặc mua những sản phẩm có giá thấp so với sản phẩm, tuy nhiên với sản phẩm thân thiện với môi trường, mang tính ưu việt và hiện đại như năng lượng mặt trời thì họ phải chấp nhận trả nhiều hơn so với sản phẩm thông thường. Độ nhận biết về sản phẩm còn thông qua hình ảnh thương hiệu của chúng trên thị trường, thương hiện là đặc tính duy nhất của một sản phẩm có thể giúp phân biệt một sản phẩm từ các sản phẩm khác của các công ty (Lanekiller, 2012), việc nhận diện và sự tin tưởng vào các doanh nghiệp năng lượng mặt trời uy tín ở Việt Nam một phần sẽ giúp người dân có sự quan tâm rõ ràng hơn với những sản phẩm năng lượng mặt trời (Shahid et al., 2017). 
Để người dân nâng cao nhận thức về sử dụng năng lượng năng lượng mặt trời dựa vào một số yếu tố ảnh hưởng sau: thứ nhất là những chính sách hỗ trợ phát triển và khuyến khích người dân sử dụng sản phẩm; thứ hai là chi phí đầu tư cho sản phẩm một cách hợp lý; thứ ba là nhận thức tính ưu việt và lợi ích của san sản phẩm; thứ tư là cần có những kiến thức hay trải nghiệm về sử dụng sản sản phẩm; và cuối cùng sử dụng nguồn năng lượng thân thiện phản ánh thái độ của người dân với môi trường.

Nâng cao nhận thức người dân về sử dụng năng lượng có thể thông qua cách tiếp cận từ góc độ văn hóa (khung văn hóa) (Khuc, 2021b). Văn hóa ở đây là văn hóa môi trường (Khuc, 2021a; Nguyen \& Vuong, 2021; Q.-H. Vuong, 2021; Q. Vuong, 2020; Q. H. Vuong, 2021; Q. H. Vuong et al., 2021). Hạt nhân văn hóa môi trường khá rộng nhưng phải bao hàm nguyên lý bán dẫn (Q. H. Vuong, 2021) được phát triển bởi Giáo sư Vương Quân Hoàng và các cộng sự. Văn hóa từ đây sẽ ảnh hưởng đến nhận thức và từ đó là hành vi của người dân liên quan đến lĩnh vực môi trường (Khuc, 2021b; Van Khuc et al., 2021).

Tóm lại, tiêu dùng xanh đang trở thành xu hướng tiêu dùng hiện nay nhằm tiết kiệm năng lượng, bảo vệ môi trường. Việc sử dụng nhiều cách tiếp cận bao gồm cách tiếp cận từ văn hóa sẽ là chìa khóa cho việc nâng cao nhận thức và hành vi tiêu dùng của người dân trong thời gian tới.

\section{Tài liệu tham khảo:}

Chính, P. M., \& Hoàng, V. Q. (2009). Kinh tế Việt Nam: Thăng trầm và đột phá. Nxb Chính trị quốc gia, Hà Nội.

Jinko. (2020). Quá khú, hiện tại và tương lai của chính sách năng lương mặt trời ở Việt Nam. https://givasolar-jinko.vn/qua-khu-hien-tai-va-tuong-lai-cua-chinh-sachnang-luong-mat-troi-o-vietnam/?fbclid=IwAR29tT25d7VEvfDSzrQ6ot5FMdgo2iSJwKiGN6KqINOf7yMD6 P8jcBDKiJA

Khuc, Q. Van. (2021a). Environmental culture thoughts to make a better world for our nature and children. OSF Preprints. https://doi.org/10.31219/osf.io/g5zex

Khuc, Q. Van. (2021b). Khucc tower: from cultural values to practical solutions. OSF Preprints. https://doi.org/10.31219/osf.io/stbj4

Lan Anh. (2021). Thúc đẩy năng lượng sạch và năng lượng tái tạo. https://www.nangluongsachvietnam.vn/d6/vi-VN/news/Thuc-day-chinh-sach-ve- 
nang-luong-tai-tao-va-nang-luong-sach-0-8-10183

Mai Trung Dũng. (2021). Một số thành tựu nổi bật sau 35 năm đổi mới đất nước.

Phutho. https://phutho.gov.vn/vi/mot-so-thanh-tuu-noi-bat-sau-35-nam-doi-moidat-nuoc

Nguyen, M.-H., \& Vuong, Q.-H. (2021). Evaluation of the Aichi Biodiversity Targets: the international collaboration trilemma in interdisciplinary research. Pacific Conservation Biology. https://doi.org/10.1071/pc21026

Phạm Sơn. (2017). Đánh thức tiềm năng điện mặt trời ở Việt Nam. https://doimoisangtao.vn/news/2017/12/1/nh-thc-tim-nng-in-mt-tri-vit-nam

Shahid, Z., Hussain, T., \& Zafar, F. (2017). The Impact of Brand Awareness on the Consumers' Purchase Intention. Journal of Accounting \& Marketing. https://doi.org/10.4172/2168-9601.1000223

Van Khuc, Q., Pham, L., Tran, M., Nguyen, T., Tran, B. Q., Hoang, T., Ngo, T., \& Tran, T. D. (2021). Understanding vietnamese farmers' perception toward forest importance and perceived willingness-to-participate in redd+ program: A case study in nghe an province. Forests, 12(5), 1-14. https://doi.org/10.3390/f12050521

Vuong, Q.-H. (2021). Western monopoly of climate science is creating an eco-deficit culture. Economy, Land \& Climate Insight, 1-9.

Vuong, Q. (2020). From children's literature to sustainability science, and young scientists for a more sustainable Earth. Journal of Sustainability Education, 24(December).

Vuong, Q. H. (2021). The semiconducting principle of monetary and environmental values exchange. Economics and Business Letters, 10(3), 284-290. https://doi.org/10.17811/ebl.10.3.2021.284-290

Vuong, Q. H., Ho, M. T., Nguyen, M. H., Pham, T. H., Vuong, T. T., Khuc, Q., Ho, H. A., \& La, V. P. (2021). On the environment-destructive probabilistic trends: A perceptual and behavioral study on video game players. Technology in Society, 65(January), 101530. https://doi.org/10.1016/j.techsoc.2021.101530 